\title{
Application of Subcritical Water Hydrolysate from Thermosetting Polyester Resin to Aqueous Agents
}

\author{
Takaharu Nakagawa ${ }^{1,2, a, *}$ and Motonobu Goto ${ }^{2, b}$ \\ 1 Eco Solution Company, Panasonic Corporation, 1048 Kadoma, Osaka 571-8686, Japan \\ 2 Department of Chemical Engineering, Nagoya University, Furo-cho, Chikusa-ku, Nagoya 464-8603, Japan \\ E-mail: anakagawa.takaharu@jp.panasonic.com (Corresponding author), bmgoto@nuce.nagoya-u.ac.jp
}

\begin{abstract}
Thermosetting polyester resin used in fiber reinforced plastic (FRP) is very difficult to be recycled since it cannot be re-molded like thermoplastic resin. In recycling thermosetting polyester resin, subcritical water with alkali was applied to hydrolyze ester bonds to obtain styrene-fumaric acid copolymer (SFC). SFC, subcritical water hydrolysate from thermosetting polyester resin, has a molecular structure of functional polymer. Alkali salt of the SFC has a same molecular structure as alkali salt of styrene-maleic anhydride copolymer (SMA) which is widely used in various kinds of high performance additives for aqueous applications. In these applications, dispersing agent, detergent builder, and surface sizing agent were selected for application of alkali salt of the SFC. The reaction product liquid contains sodium salt of SFC (SFC-Na). It was evaluated as dispersing agent and detergent builder. Ammonium salt of SFC $\left(\mathrm{SFC}-\mathrm{NH}_{4}\right)$ was evaluated as surface sizing agent for paper. The evaluation results were compared with that of commercial additives to verify the possibility to substitute them. The reaction product liquid showed superior dispersing effect to commercial dispersing agent for hydrophobic powder. It also showed superior alkali buffering capacity to commercial detergent builder. SFC-NH $\mathrm{N}_{4}$ showed higher sizing effect than commercial sizing agent.
\end{abstract}

Keywords: Thermosetting polyester resin, recycling, styrene-fumaric acid copolymer, dispersing agent, detergent builder, surface sizing agent.

ENGINEERING JOURNAL Volume 19 Issue 5

Received 3 December 2014

Accepted 23 February 2015

Published 31 October 2015

Online at http://www.engj.org/

DOI:10.4186/ej.2015.19.5.1 


\section{Introduction}

Thermosetting polyester resins are generally used in fiber reinforced plastics (FRP) with glass fibers and inorganic fillers. FRP has been applied to various products, such as boats, tanks, and motors. FRP is also widely applied to bathtubs in Japan. Thermosetting resins cannot be re-molded like thermoplastic resins. The high content of inorganic material in FRP creates difficulties in incineration. Therefore, most FRPs have been landfilled. Environmental legislation such as the EU-directives also requires true material recycling of FRP. However, no chemical recycling technology of thermosetting polyester resins into raw materials for resins or other organic compounds has been commercialized.

Chemical recycling of thermosetting polyester resins is worth considering not only for a view point of horizontal recycling into resin raw material, but also for up-grading recycling into higher value product such as functional polymer. Styrene chains form during the curing process of unsaturated polyesters, which have higher value than the resin raw materials. If all ester bonds trapping the styrene chains are hydrolyzed, styrene-fumaric acid copolymer (SFC) should be obtained. The molecular structure of SFC is similar to that of styrene-maleic anhydride copolymer (SMA), which is widely used in various high performance additives. $[1,2]$ Moreover, the SMA could become more expensive in near future due to the demand-supply gap of benzene, the raw material of styrene, which cannot be produced from shale gas. Such valuable materials are now wastefully landfilled.

There are various strategies for recycling FRP. In the grinding method, mechanically ground FRP is applied as inorganic filler in concrete, cement components, plastic, etc. [3-5]. In the thermolysis method, glass fiber and/or inorganic filler are recovered after pyrolysis or combustion [6-9]. In these approaches, thermosetting resin is not recovered as precursor for new resins.

Various chemical recycling approaches of FRP such as solvolysis have also been studied. Diethylene glycol monomethyl ether (DGMM) and benzyl alcohol (BZA) [10], glycol [11-13], amino alcohols, and polyamines $[14,15]$ were investigated. Supercritical methanol was also applied to recover dimethyl phthalate (DMP) [16-20].

Water has also been applied as an agent for chemical recycling of FRP. Superheated steam [21] and subcritical water $[22,23]$ have been used to recover glass fibers. Oliveux et al. used subcritical water to recover propylene glycol and phthalic acid [24, 25]. Suyama et al. also used subcritical water to recover hydroxyl compounds having a long alkyl chain and alkyl amines [26, 27]. We have reported that subcritical hydrolysis of thermosetting polyester resin at $360^{\circ} \mathrm{C}, 18.7 \mathrm{MPa}$. Only glycols and fumaric acids were recovered [28].

In some of the above chemical recycling approaches, material recycling of the resin was demonstrated. However, all of them are horizontal recycling methods that recover resin raw materials such as glycol and phthalic acid and re-crosslink them with new resin raw materials. There has been no method to recover $\mathrm{SFC}$ as a functional polymer from the thermosetting polyester resin waste and apply it to high performance additives.

We reported that SFC was recovered by subcritical hydrolysis of the thermosetting polyester resin [2931]. Subcritical water is well known to have significant reactivity [32]. We have successfully demonstrated that most of ester bonds of the thermosetting polyester resin were hydrolyzed efficiently using subcritical water with alkali to recover SFC in high yield [29-31].

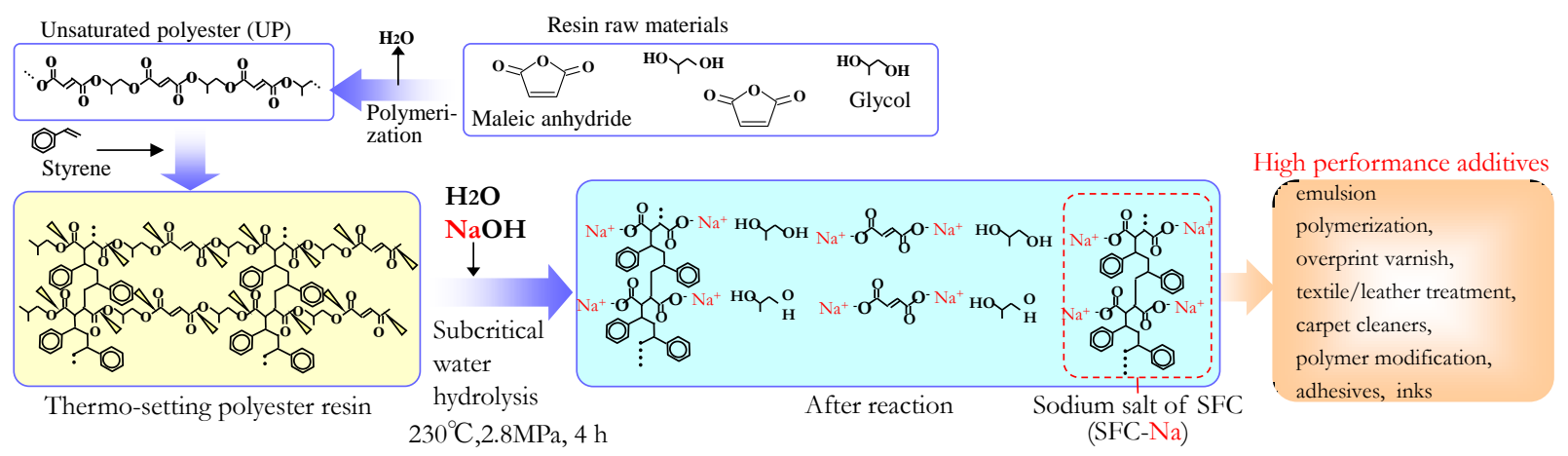

Fig. 1. Concept of recycling thermosetting polyester resin using subcritical water with $\mathrm{NaOH}$. 
Figures 1 and 2 show a concept of recycling thermosetting polyester resin using subcritical water with $\mathrm{NaOH}$ and experimental samples, respectively.
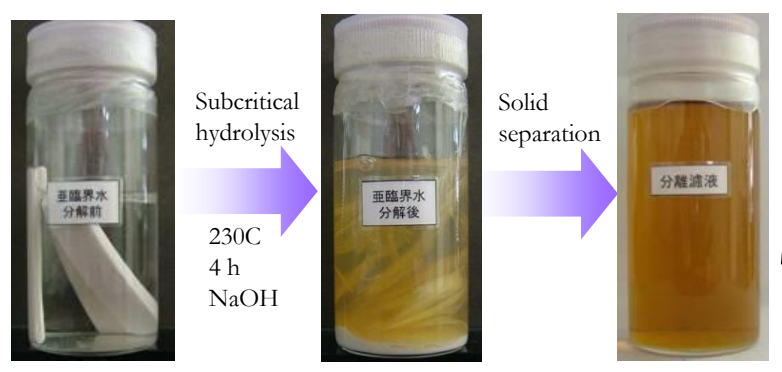

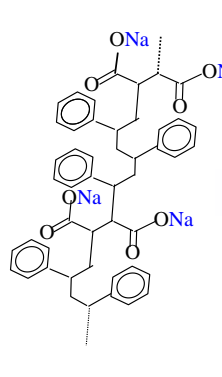

Sodium salt of SFC
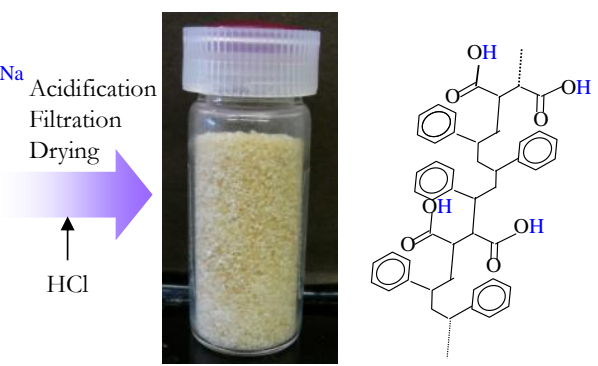

Styrene Fumaric acid Copolymer(SFC)

Fig. 2. Experimental samples of subcritical hydrolysis of thermosetting polyester resin.

Thermosetting polyester resin is obtained by crosslinking unsaturated polyester (UP) polymer with styrene. Firstly, glycol and maleic anhydride were polyesterified to produce unsaturated polyester (UP). Maleic anhydride is used as the UP raw material, which was isomerized to fumaric acid during polyesterification. [1-1] Styrene is added to the UP to produce UP resin which is very viscous liquid. The UP resin is mixed with glass inorganic materials such as glass fiber and inorganic filler then is cured. In general, $\mathrm{CaCO}_{3}$ and/or $\mathrm{Al}(\mathrm{OH})_{3}$ are used as inorganic filler. Then, styrene reacts with the fumaric acid of the UP to form a styrene bridge and three dimensional resin matrix during curing process. It is called thermosetting polyester resin. The thermosetting polyester resin was hydrolized at $230^{\circ} \mathrm{C}, 2.8 \mathrm{MPa}, 4$ hours using subcritical water. After the reaction, SFC is dissolved in the reaction liquid as sodium salt (SFC-Na). SFC-Na has practically the same molecular structure as alkali salt of styrene-maleic anhydride (SMA) which is widely used in various aqueous agents, such as dispersing agent, surface sizing agent, detergent agent, chelating agent, emulsifying agent, and so on. [1,2] Therefore, the alkali salt of SFC should have a highly potential for applying to such applications.

In this paper, the reaction product liquid containing sodium salt of SFC (SFC-Na), glycol, fumaric acid, and other organic acids was evaluated as dispersing agent for hydrophilic and hydrophobic powders and as detergent builder. Ammonium salt of SFC $\left(\mathrm{SFC}-\mathrm{NH}_{4}\right)$ was evaluated as surface sizing agent. The evaluation result was compared with that of commercial additives to verify the possibility to substitute them

\section{Material and Method}

\subsection{Dispersing Agent}

The target powders were kaolin and $\mathrm{CaCO}_{3}$ as hydrophilic inorganic pigment, and phthalocyanine blue as hydrophobic organic pigment. Molecular formula and picture of phthalocyanine blue were described in Scheme 1.

To verify the possibility of SFC-Na applying to dispersing agent, dispersing agent was dissolved in water with $4 \mathrm{wt} \%$ concentration to produce dispersing agent solution.

Scheme 1. Molecular formula of phthalocyanine blue.

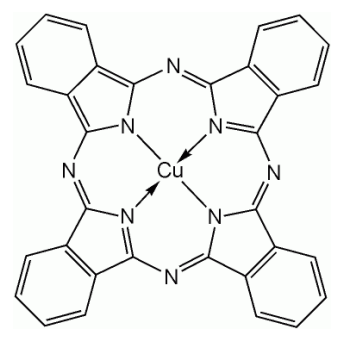

In the case of reaction liquid, the SFC-Na in the reaction liquid was defined as dispersing agent. A target powder was mixed with the dispersing agent solution. Target powder: the dispersing agent solution was 1:10. They were stirred for $1 \mathrm{~min}$. at 15,000 rpm by homogenizer (HG-200, AS ONE Corporation). 
After stirring, the liquid containing the powder was filtered by $0.2 \mu \mathrm{m}$ mesh membrane filter to remove excessive dispersing agent solution. The filtered powder was dried at $105^{\circ} \mathrm{C}$ for 1 hour. The dried powder, untreated powder, and dispersing agent solid after drying the dispersing agent solution were evaluated by heat analysis to quantify how much the dispersing agent adsorbed on the powder by calculation based on the weight loss curve of the TG-DTA.

In evaluation of dispersibility, each dispersing agent solution sample with targeting powder after stirring was filtered by different membrane filters designed to filter the powder over $0.45 \mu \mathrm{m}$ and $1.2 \mu \mathrm{m}$. The powder weight filtered by each membrane filter was measured. They were substituted from initial powder weight to obtain the powder weight passed through $0.45 \mu \mathrm{m}$ membrane filter. More powder weight passed through the membrane filter indicates higher dispersibility. Syringe filters, minisart (Sartrius stedim) was used as membrane filters. Targeting powders were kaolin, $\mathrm{TiO}_{2}$, and $\mathrm{CaCO}_{3}$ as hydrophilic inorganic pigment, and phthalocyanine blue as hydrophobic organic pigment. At first, $0.1 \mathrm{~g}$ of powder and $10 \mathrm{~g}$ of the dispersing agent solution sample with the dispersing agent concentration of $0.5 \mathrm{wt} \%$ were put in the $30 \mathrm{cc}$ test bottle. Total weight of the dispersing agent was considered to be $0.05 \mathrm{~g}$. They were stirred for 3 minutes by homogenizer with 15,000 rpm. Water was added to them until total weight reached $20 \mathrm{~g}$. After stirring, they were stayed for 5 minutes and then were filtered by membrane filter. Firstly, they were filtered with $1.2 \mu \mathrm{m}$ membrane filter. The dispersing agent solution sample containing the target powder passed through $1.2 \mu \mathrm{m}$ membrane filter was stirred again and then filtered with $0.45 \mu \mathrm{m}$ membrane filter.

\subsection{Detergent Builder}

As detergent builder, calcium $(\mathrm{Ca})$ ion trapping ability and alkali buffering capacity were evaluated. For evaluation of $\mathrm{Ca}$ ion trapping ability, $50 \mathrm{~mL}$ of aqueous solutions which have $0.05 \%$ of solid content of detergent builder and pure water were prepared at the beginning. In the case of reaction product liquid, SFC-Na content was defined as solid content of detergent builder. Secondary, $0.25 \mathrm{~mL}$ of aqueous solution of n-alkyl-benzene sulfonic acid with concentration of $10 \%$ was added to them. $\mathrm{NaOH}$ or $\mathrm{HCl}$ with concentration of $0.1 \mathrm{~mol} / \mathrm{L}$ was added to them to control $\mathrm{pH}$ level to achieve $\mathrm{pH} 10$ to produce a sample solution. Then calcium acetate solution had been dropped to the sample solution with stirring until they became white. Concentration of calcium acetate was $1 \%$ based on calcium acetate monohydrate. The total volume of calcium acetate solution was measured as titer. Ca ion trapping ability is defined as Eq. (1)

$$
Q=M \frac{v m}{w}
$$

where $Q$ : Ca ion trapping ability $\left(\mathrm{CaCO}_{3} \mathrm{mg} / \mathrm{g}\right) ; M$ : Molar mass of $\mathrm{CaCO}_{3} ; v$ : total volume of titer $(\mathrm{mL})$; $m: \mathrm{mol}$ of $\mathrm{Ca}$ ion per unit volume of titer; $w$ : total weight of detergent builder (g).

For evaluation of alkali buffering capacity, $50 \mathrm{~mL}$ of the above detergent builder solutions which have $2 \%$ of solid content and pure water were prepared. Secondary, $\mathrm{NaOH}$ or $\mathrm{HCl}$ of $0.1 \mathrm{~mol} / \mathrm{L}$ was added to control $\mathrm{pH}$ level to achieve $\mathrm{pH} 10$. Then $0.1 \mathrm{~mol} / \mathrm{L}$ of $\mathrm{HCl}$ had been dropped to the solution with stirring until they reached $\mathrm{pH}$ 8. The titer was defined as alkali buffering capacity $(\mathrm{mL})$

\subsection{Surface Sizing Agent}

To verify the possibility of SFC-NH 4 applying to surface sizing agent, the commercial SA\#1 containing styrene skeleton as hydrophobic region as same as the SFC was used. Styrene amount dispersed on the paper surface per unit area is considered to affect water repellency effect. Adsorbed weight of sizing agent per unit area (i) was multiplied with number of moles per unit weight of sizing agent obtained by NMR analysis (ii) to calculate number of moles per unit area (iii). 


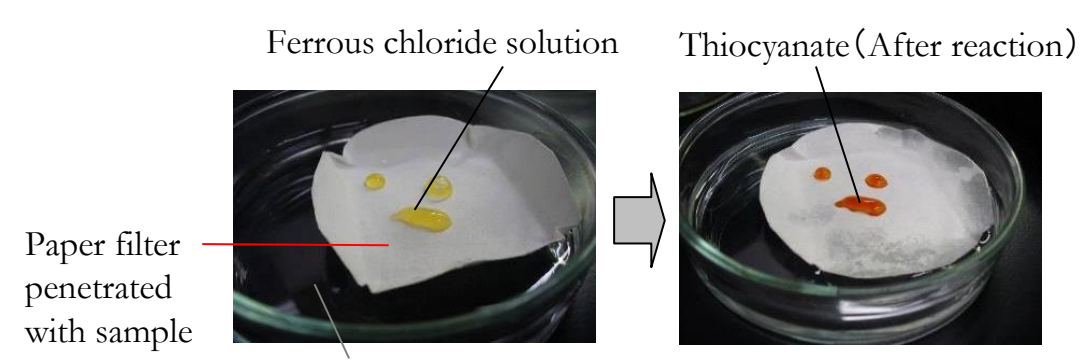

Ammonium thiocyanate solution

Fig. 3. Stôckigt sizing method.

Surface sizing effect was evaluated based on stőckigt method (JIS P8812) described in Fig. 3. A given amount of surface sizing agent solution sample was penetrated in paper filter and they were dried. The dried paper filter was put on the surface of ammonium thiocyanate solution. Ferrous chloride solution was dropped and then reacted with ammonium thiocyanate solution to be converted to thiocyanate with color changing to red. The transient time of changing color to red was measured as stőckigt sizing degree and compared with commercial SD\#1. Longer transient time indicates higher surface sizing effect base on water repellency.

\section{Results and Discussion}

\subsection{Reaction Product Liquid and Commercial Additives}

Table 1(a) shows molecular formula and weight averaged molecular weight in terms of polyethylene glycol $(\mathrm{Mw})$ of commercial dispersing agent (DA) and reaction product liquid. Polyacrylic sodium salt which has 5,000 of Mw was selected as commercial DA \#1 targeting for hydrophilic powders. Styrene-sodium malatemethyl methacrylate copolymer was selected as commercial DA \#2 targeting for hydrophobic powders. It also has styrene skeleton which is seemed to be effective for poising the surface of hydrophobic powder. Reaction product liquid contains sodium salt of SFC-Na and glycol, fumaric acid and other organic acids derived from degradation of fumaric acid. Mw of SFC-Na was 80,000 in terms of polyethylene glycol and was the largest among samples.

Table 1(b) shows molecular formula and $\mathrm{Mw}$ of commercial detergent builder (DB), commercial surface sizing agent $(\mathrm{SA})$, and $\mathrm{SFC}-\mathrm{NH}_{4}$. Polyacrylic sodium salt which has 22,000 of $\mathrm{Mw}$ was selected as commercial DB\#1 Styrene-ammonium acrylate copolymer was selected as commercial SA\#1. It has both hydrophilic region of ammonium acrylate and strong hydrophobic region of styrene skeleton.

Table 1(a) Commercial dispersing agent (DA), reaction product liquid.

\begin{tabular}{|c|c|c|c|}
\hline Sample & Commercial DA \#1 & Commercial DA \#2 & Reaction product liquid (PL) \\
\hline Material & Polyacrylic sodium salt & $\begin{array}{l}\text { Styrene-sodium malate-methyl } \\
\text { methacrylate copolymer }\end{array}$ & $\begin{array}{l}\text { Sodium salt of SFC } \\
\text { (with glycol, fumaric acid, etc.) }\end{array}$ \\
\hline $\begin{array}{l}\text { Molecular } \\
\text { formula }\end{array}$ & $\left(\begin{array}{rl}\mathrm{CH}_{2}-\underset{\mathrm{C}}{\mathrm{C}} \mathrm{H} \\
\mathrm{O}=\mathrm{O} \\
\mathrm{ONa}\end{array}\right)_{\mathrm{n}}$ & 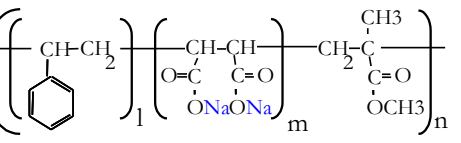 & 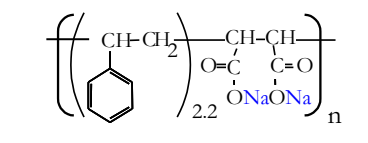 \\
\hline $\mathrm{Mw}^{*}$ & 5,000 & 10,000 & 80,000 \\
\hline
\end{tabular}


Table 1(b). Commercial detergent builder(DB) and surface sizing agent (SA), SFC-NH4.

\begin{tabular}{|c|c|c|c|}
\hline Sample & Commercial DB \#1 & Commercial SA \#1 & SFC-NH4 \\
\hline Material & Polyacrylic sodium salt & $\begin{array}{l}\text { Styrene-ammonium } \\
\text { acrylate copolymer }\end{array}$ & Ammonium salt of SFC \\
\hline $\begin{array}{l}\text { Molecular } \\
\text { formula }\end{array}$ & $\left(\begin{array}{r}\mathrm{CH}_{2}-\underset{\mathrm{C}}{\mathrm{C}=\mathrm{O}} \\
\mathrm{O} \\
\mathrm{ONa}\end{array}\right)$ & $\left.\mathrm{H}_{2}\right)$ & $\left(\begin{array}{c}\mathrm{CH}-\mathrm{CH}_{2} \\
\end{array}\right) \underset{\mathrm{O}=\stackrel{\mathrm{C}}{\mathrm{C}}-\mathrm{C}=\mathrm{O}}{\mathrm{C}}-\mathrm{O}$ \\
\hline $\mathrm{Mw}^{*}$ & 22,000 & 40,000 & 80,000 \\
\hline
\end{tabular}

$\mathrm{Mw}^{*}$ :Weight averaged molecular weight (in terms of polyethylene glycol)

\subsection{Dispersing Agent}

Molecular formula of sodium salt of the SFC (SFC-Na) are described in Scheme 2. SFC-Na has styrene skeleton as a hydrophobic region and sodium carboxylate as a hydrophilic region. Figure 4 shows hypothetic mechanism of SFC-Na as dispersing agent. Powders tend to be agglomerated each other by intermolecular force. Surface of powder is charged positive. Carbonyl ion of SFC-Na is negatively charged and is attached to positive charge powder surface. Powder surface is covered by SFC-Na which have negative charge. Electrostatic repulsion is developed between each negatively charged powders. The electrostatic repulsion is expected to prevent agglomeration and to increase dispersibility. Steric hindrance caused by SFC-Na is also expected to prevent agglomeration.
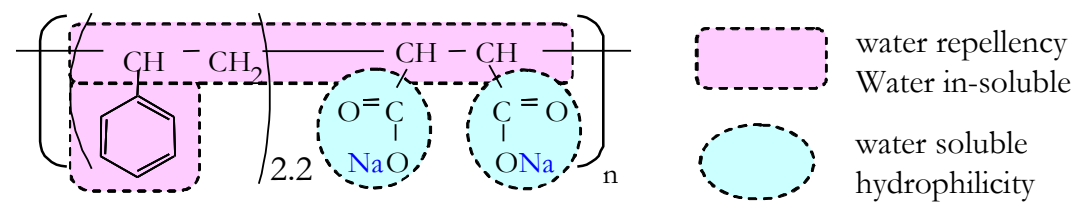

Scheme 2. Molecular formula of sodium salt of SFC (SFC-Na).

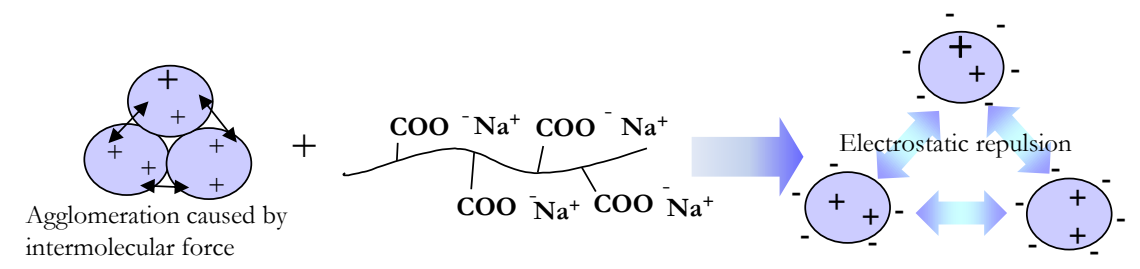

Fig. 4. Hypothetic mechanism of SFC-Na as dispersing agent.

Figure 5 shows hypothesis for mechanism of SFC-Na as dispersing agent for hydrophobic powder. Hydrophobic powder cannot be dispersed in water since hydrophobic surface has no affinity to water molecule. Hydrophobic materials tend to be agglomerated each other since water molecule cannot access the surface. Dispersing agent should have hydrophobic region and a hydrophilic region. Hydrophobic region of SFC-Na is poised on the surface of hydrophobic powder. Hydrophilic region of SFC-Na is expected to provide water solubility acting like cilium.

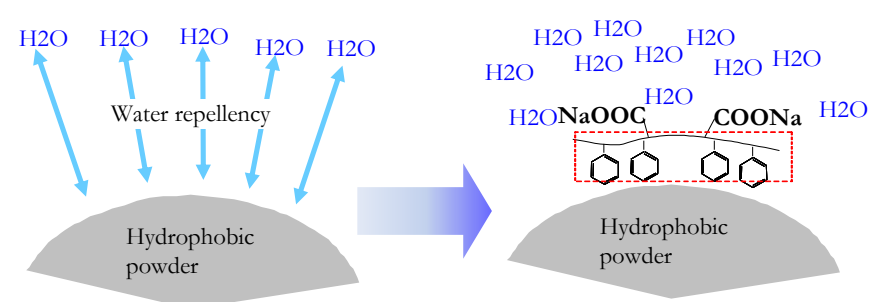

Fig. 5. Hypothesis for mechanism of SFC-Na as dispersing agent for hydrophobic powder. 
Table 3 shows evaluation results of dispersing agent adsorption on each powder. As described in Fig. 4 and Fig. 5, the dispersing agent is required to adsorb the powder surface to express dispersing effect. The adsorbed amount of SFC in reaction product liquid was more than that of both commercial DA\#1 and DA\#2. Therefore, the reaction product liquid is expected to have a dispersing effect for both powders.

Table 3. Dispersing agent (DA) adsorption on each powder.

\begin{tabular}{|l|c|c|c|}
\hline Powder & Reaction liquid & Commercial DA \#1 & Commercial DA \#2 \\
\hline Kaolin (hydrophilic pigment) & 8.1 & 2.5 & - \\
\hline $\mathrm{CaCO}_{3}$ (hydrophilic pigment) & 5.1 & 3.1 & - \\
\hline Phthalocyanine blue (hydrophobic pigment) & 11.1 & - & 7.5 \\
\hline
\end{tabular}

Filtering test result for kaolin, $\mathrm{TiO}_{2}, \mathrm{CaCO} 3$, and phthalocyanine blue were described in Figs 6 (a), (b), (c), and (d), respectively. In case of all targeting powder, particle size of most of powder without the dispersing agent was over $1.2 \mu \mathrm{m}$. If the dispersing agent is effective, the weight of particle size over 1.2 $\mu \mathrm{m}$ should be decreased. Total weight of the dispersing agent was $0.05 \mathrm{~g}$. Most of them were considered to have particle size less than $0.45 \mu \mathrm{m}$.

In filtering test result for kaolin described in Fig. 6(a), the reaction product liquid almost did not show a dispersing effect for kaolin even weight of particle size range between $0.45 \mu \mathrm{m}$ and $1.2 \mu \mathrm{m}$ was slightly increased. Commercial DA\#1 showed a slight dispersing effect.

In filtering test result for $\mathrm{TiO}_{2}$ described in Fig. 6 (b), the reaction liquid showed a slight dispersing effect. However, the dispersing effect of commercial DA\#1 was larger than reaction liquid.

In filtering test result for $\mathrm{CaCO}_{3}$ described in Fig. 6 (c), reaction liquid showed a slight dispersing effect. Commercial DA\#1 almost didn't show a dispersing effect. It was concluded that the dispersing effect of the reaction liquid for hydrophilic powders were small.

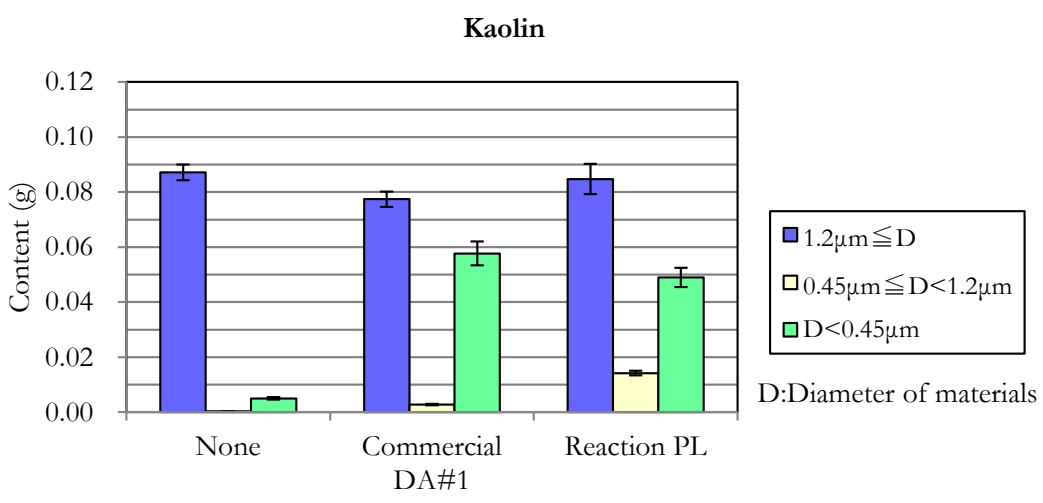

Fig. 6(a). Filtering test result (Kaolin).

$\mathrm{TiO}_{2}$

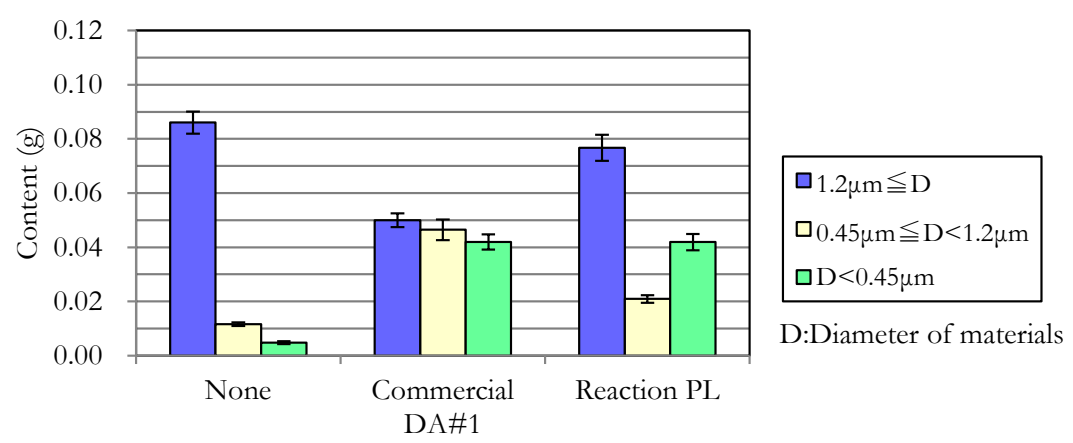

Fig. 6(b). Filtering test result $\left(\mathrm{TiO}_{2}\right)$. 


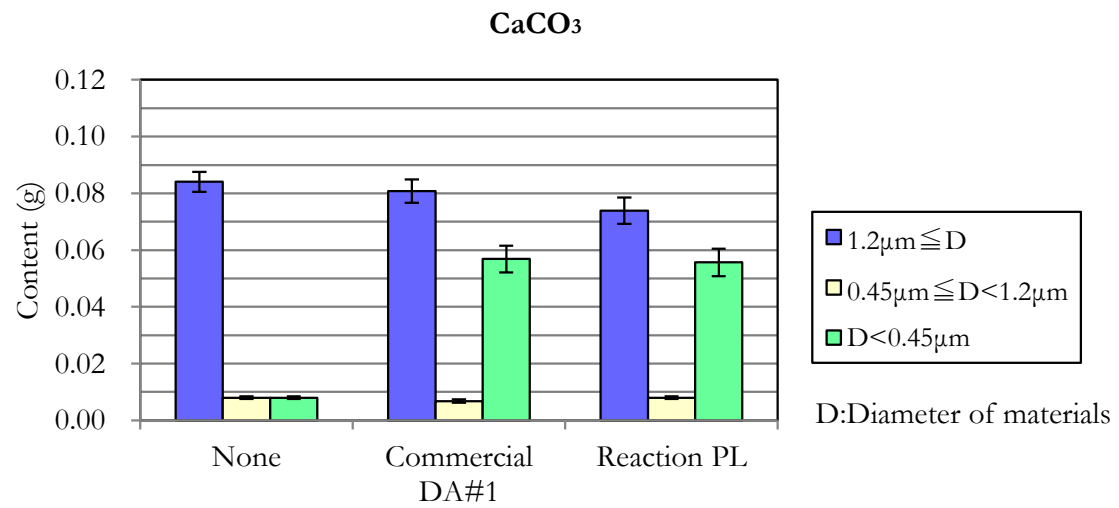

Fig. 6(c). Filtering test result $\left(\mathrm{CaCO}_{3}\right)$.

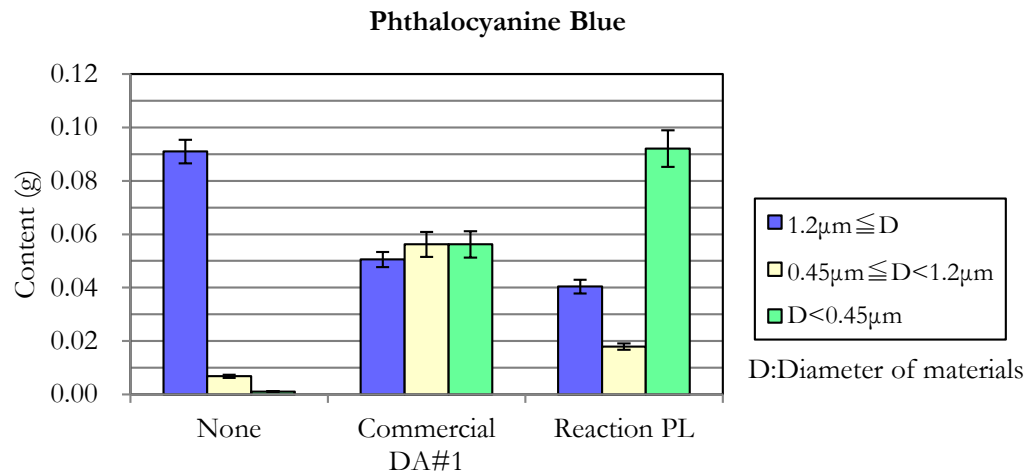

Fig. 6(d). Filtering test result (Phthalocyanine_Blue).

The dispersing effect mechanism by SFC-Na for hydrophilic powders is considered electrostatic repulsion and steric hindrance. Amount of carbonyl ion per unit weight of SFC-Na is less than that of commercial DA\#1. It is assumed insufficient although its adsorption amount was more than commercial DA\#1. Mw is also suggested to be important factor for uniform distribution on powder surface. $\mathrm{Mw}$ of SFC-Na is assumed to be too large to be distributed uniformly to create the dispersing effect.

Figure 6(d) shows filtering test result of phthalocyanine blue. It was obvious that the weight of particle size over $1.2 \mu \mathrm{m}$ was decreased by reaction liquid to indicate the dispersing effect. The weight of particle size over $1.2 \mu \mathrm{m}$ of commercial DA\#2 was also decreased. However, the weight of particle size less than $0.45 \mu \mathrm{m}$ of the reaction product liquid was much more than that of commercial DA\#2. The reaction product liquid has the powder finer than commercial DA\#2. Styrene skeleton of the SFC-Na seemed to have sufficient affinity with styrene skeleton of the phthalocyanine blue. Dicarboxylic sodium salt of the SFC-Na seemed to provide the powder with dispersibility on water. Commercial DA\#2 also has styrene skeleton and dicarboxylic sodium salt. However, their ratio is unknown. It is suggested that the ratio of hydrophobic region and hydrophilic region affected to dispersing effect. $\mathrm{Mw}$ might be also another factor for dispersing effect.

The reaction product liquid successfully demonstrated the superior dispersing effect for phthalocyanine blue to commercial SD\#2. It was concluded that the reaction product liquid was verified the possibility for applying to the dispersing agent for hydrophobic powders.

\subsection{Detergent Builder}

Figure 7 shows hypothesis for mechanism of SFC-Na trapping $\mathrm{Ca}$ ion as dispersing agent. Dicarboxyl sodium salt is expected to trap $\mathrm{Ca}^{2+}$ effectively. 


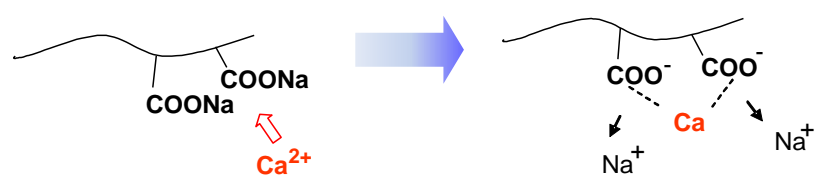

Fig. 7. Hypothesis for mechanism of SFC-Na for trapping calcium (Ca) ion.

Figure 8 shows the evaluation result of $\mathrm{Ca}$ ion trapping ability. The reaction product liquid showed higher $\mathrm{Ca}$ ion trapping ability than pure water with no detergent builder. Carbonyl ion of SFC-Na seemed to trap $\mathrm{Ca}^{2+}$ effectively. Commercial DB\#1 showed higher performance than the reaction product liquid. The commercial DB\#1 has the higher molar ratio of carbonyl ion per unit weight than SFC-Na. It is assumed to affect the higher Ca ion trapping ability.

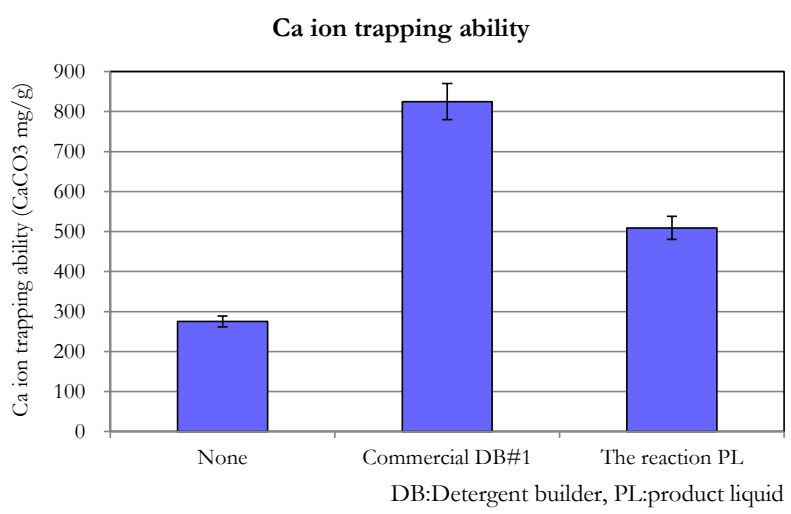

Fig. 8. Evaluation result of Ca ion trapping ability.

Figure 9 shows the evaluation result of alkali buffering capacity. The reaction product liquid showed significant performance. Alkali buffering capacity of the reaction product liquid was much higher than commercial DB\#1. In the reaction product liquid, there were certain amounts of carboxylic acid sodium salt other than the sodium salt of SFC. Sodium salt of fumaric acid and other carboxylic acid such as maleic acid, glycolic acid, acetic acid, and so on. It was suggested that they also contributed to buffer alkali.

The reaction product liquid successfully demonstrated the superior alkali buffering capacity to commercial DB\#1. It also showed Ca ion trapping ability. It was concluded that the reaction product liquid was verified the possibility for applying to the detergent builder.

Alkali buffering capacity

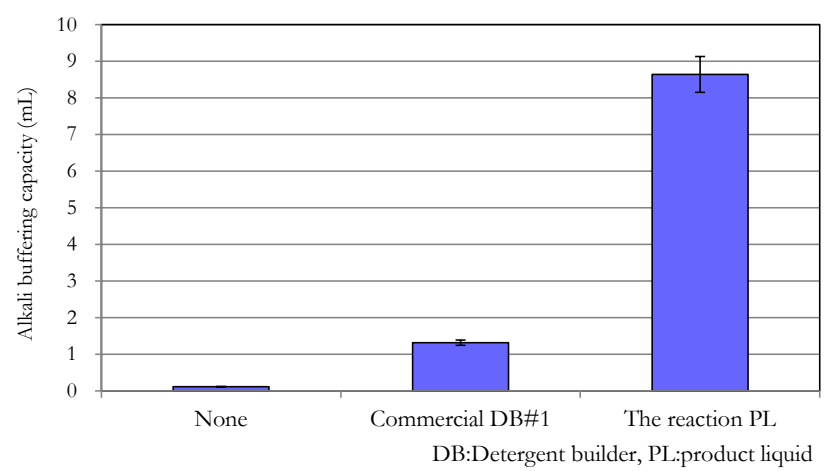

Fig. 9. Evaluation result of alkali buffering capacity.

\subsection{Surface Sizing Agent}

In the case of surface sizing agent, ammonia was used as alkali of SFC instead of Na. Figure 10 shows hypothetic mechanism of SFC- $\mathrm{NH}_{4}$ as surface sizing agent. Paper surface is hydrophilic due to $\mathrm{OH}$ group of cellulose. Firstly, SFC-NH 4 is dispersed uniformly on paper surface due to its hydrophilic ammonium carboxylate. After dispersion, ammonia is vaporized to produce carboxyl acid which is less hydrophilic than 
ammonium carboxylate then SFC is fixed on paper surface. Hydrophobic region of the SFC is expected to provide water repellency.

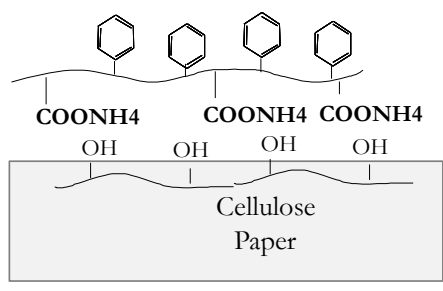

Dispersing

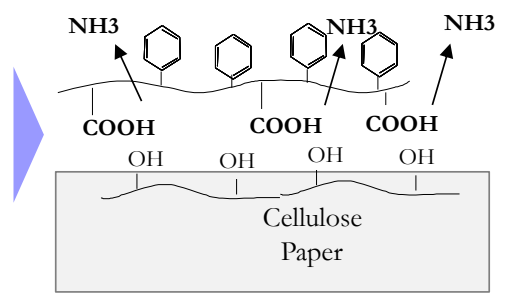

NH3 vaporizing

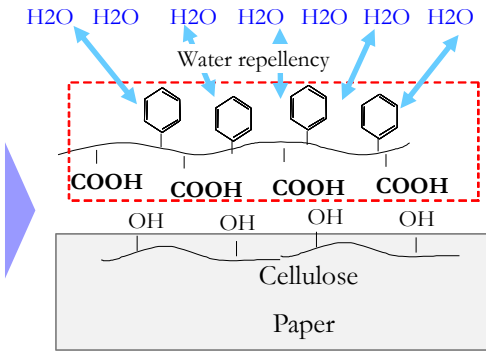

Stable stage

Fig. 10. Hypothetic mechanism of $\mathrm{SFC}_{-} \mathrm{NH}_{4}$ as surface sizing agent.

Table 4. Surface sizing agent (SA) adsorption comparison.

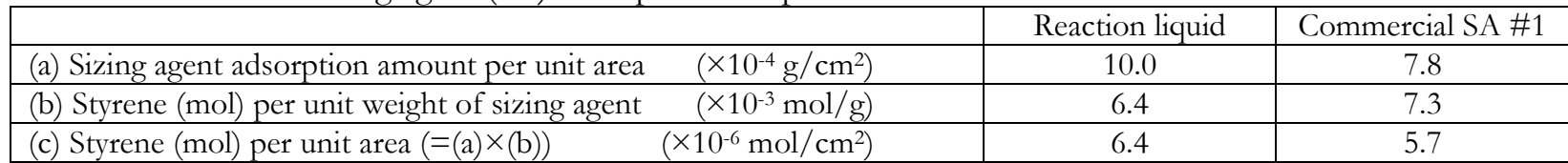

Table 4 shows the evaluation result of number of styrene moles per unit area in paper. Styrene (mol) per unit weight of the reaction liquid was less than that of commercial SD\#1. However, adsorption amount per unit area of the reaction product liquid was larger than that of commercial SD\#1. The difference was assumed to be caused by the molar ratio of carbonyl ion and styrene. SFC has di-carbonyl ion and commercial SD\#1 has mono-carbonyl ion. The higher molar ratio of carbonyl ion provides higher hydrophilicity to contribute to increase adsorption amount on paper. SFC-NH $\mathrm{NH}_{4}$ totally provided more amount of styrene to paper than commercial SA\#1. Therefore, it was expected to create a surface sizing effect equivalent to commercial SA\#1.

Figure 11 shows the Stőckigt sizing test result. In the case of no additive, dropped ferrous chloride solution was immediately reacted with ammonium thiocyanate solution, thus infiltration time was 0 sec. In the case that the paper filter was penetrated with the reaction product liquid containing mainly SFC-Na, it showed a slightly sizing effect due to its styrene skeleton although SFC-Na itself was hydrophilic entirely. In the case of SFC-NH , it showed higher sizing effect than commercial SD\#1. It was assumed that larger amount of styrene per unit area of SFC-NH 4 than commercial SD\#1 contributed the higher sizing effect.

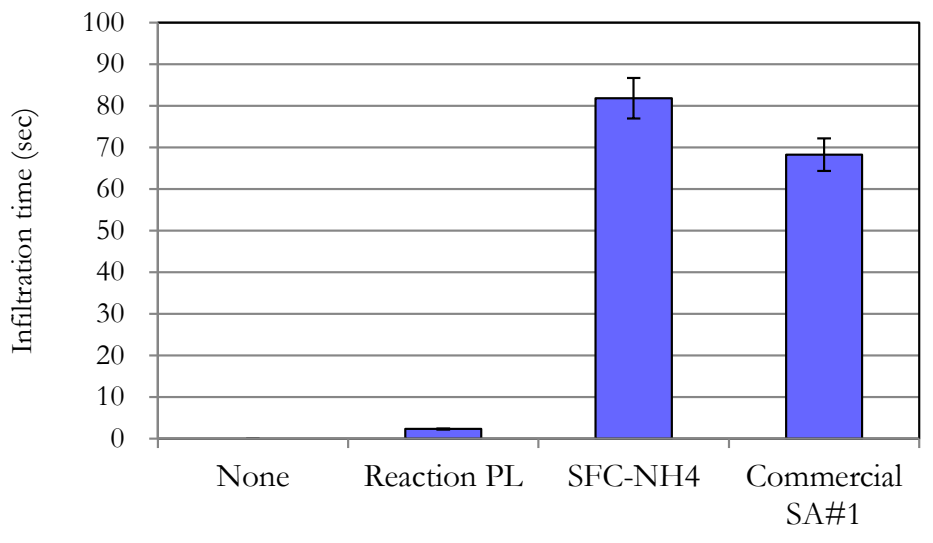

SA: Surface Sizing Agent, PL:product liquid

Fig. 11. Stőckigt sizing test result.

The SFC-NH 4 successfully demonstrated the superior surface sizing effect than commercial SD\#1. It is concluded that the SFC-NH${ }_{4}$ was verified the possibility to be applied to surface sizing agent. However, in the case of $\mathrm{SFC}_{-} \mathrm{NH}_{4}$, paper was slightly colored by unknown impurities. It has to be improved. 


\section{Conclusion}

In verification of applying to dispersing agent, the reaction product liquid showed less dispersing effect than commercial DA\#1 for hydrophilic powder such as kaolin, $\mathrm{TiO}_{2}$, and $\mathrm{CaCO}_{3}$. On the other hand, the reaction product liquid showed superior dispersing effect to commercial DA\#2 for phthalocyanine blue. Styrene skeleton of SFC-Na is assumed to contribute to increase the dispersing effect. The reaction product liquid has the possibility for applying to the dispersing agent for hydrophobic powders.

In verification of applying to detergent builder, the reaction product liquid showed superior alkali buffering capacity to commercial DB\#1. It also showed Ca ion trapping ability. The reaction product liquid has the possibility for applying to the detergent builder.

In verification of applying to surface sizing agent, $\mathrm{SFC}-\mathrm{NH}_{4}$ showed higher sizing effect than commercial SA\#1. SFC-NH $\mathrm{NH}_{4}$ has possibility to be applied to surface sizing agent.

It was concluded that SFC alkali salt has a potential to substitute to the commercial high performance additives. The SFC is expected to be applied to other applications widely.

\section{Acknowledgement}

The research was supported by the New Energy and Industrial Technology Development Organization (NEDO).

\section{References}

[1] Kawahara Petrochemical Co., Ltd. Home Page. [Online]. Available: http://www.kawahara.co.jp/sma.html (in Japanese).

[2] Cray Valley USA, LLC, Home Page, SMA. [Online]. Available: http://www.crayvalley.com/products/sma-styrene

[3] P. Asokan, M. Osmani, and A. D. F. Price, "Assessing the recycling potential of glass fibre reinforced plastic waste in concrete and cement composites," J Cleaner Production, vol. 17, pp. 821-829, 2009.

[4] S. Nakai, Y. Tokumou, S. Tsukawaki, T. Okuda, W. Nishijima, and M. Okada, "Recycling of waste FRP as filler for new FRP products," in 6th International Symposium on Feedstock Recycling of Pobmeric Materials, Toledo, Spain, 2011, pp. 165-166.

[5] M. C. S. Ribeiro, A. Fiúza, M. L. Dinis, A. C. M. Castro, F. G. Silva, J. P. Meixedo, and M. R. Alvim, "Experimental study on polyester based concretes filled with glass fibre reinforced plastic recyclatesA contribution to composite materials sustainability," in 19th Annual International Conference on Composites or Nano Engineering, Shanghai, China, 2011, pp. 961-962.

[6] S. J. Pickering, R. M. Kelly, J. R. Kennerley, C. D. Rudd, and N. J. Fenwick, "A fluidised-bed process for the recovery of glass fibres from scrap thermoset composites," Compos. Sci. Technol, vol. 60, pp. 509-523, 2000.

[7] G. Grause, T. Mochizuki, T. Kameda, and T. Yoshioka, "Recovery of glass fibers from glass fiber reinforced plastics by pyrolysis," J Mater Cycles Waste Manag, vol. 15, pp. 122-128, 2013.

[8] A. Torres, I. DeMarco, B. M. Caballero, M. F. Laresgoiti, and M. J. Chomo'n, "Recycling of the solid residue obtained from the pyrolysis of fiberglass polyester sheet molding compound," Adv. Polym. Techn., vol. 28, no. 2, pp. 141-149, 2009.

[9] H. Shima, H. Takahashi, and J. Mizuguchi, "Recovery of glass fibers from fiber reinforced plastics," Mater. Trans., JIM, vol. 52, no. 6, pp. 1327-1329, 2011.

[10] T. Iwaya, S. Tokuno, M. Sasaki, M. Goto, and K. Shibata, "Recycling of fiber reinforced plastics using depolymerization by solvothermal reaction with catalyst," J. Mater. Sci., vol. 43, pp. 2452-2456, 2008.

[11] S. Kubota and O. Ito, "Feedstock recyclibility of cured unsaturated polyester waste using glycol," in The 1st International Symposium on Feedstock Recycling of Plastics, Sendai, Miyagi, Japan, 1999, pp. 247-250.

[12] K. H. Yoon, A. T. DiBenedettot, and S. J. Huang, "Recycling of unsaturated polyester resin using propylene glycol," Polymer, vol. 38, no. 9. pp. 2281-2285, 1997.

[13] S. Kubota, H. Mori, and K. Maeda, "Chemical recycling of unsaturated polyester wastes by decomposition in glycol," Network Polymer, vol. 24, no. 1, pp. 22-29, 2003 (in Japanese).

[14] M. Vallee, G. Tersac, N. Destais-Orvoen, and G. Durand, "Chemical recycling of class a surface quality sheet-molding," Ind. Eng. Chem. Res., vol. 43, pp. 6317-6324, 2004. 
[15] D. Perrin, C. Guillermain, A. Bergeret, J. M. Lopez-Cuesta, and G. Tersac, "SMC composites waste management as reinforcing fillers in polypropylene by combination of mechanical and chemical recycling processes," J. Mater. Sci., vol. 41, pp. 3593-3602, 2006.

[16] A. Kamimura, K. Yamada, T. Kuratoni, Y. Taguchi, and F. Tomonaga, "Effective depolymerization waste FRPs by treatment with DMAP and supercritical alcohol," Chem. Lett., vol. 35, pp. 586-587, 2006.

[17] A. Kamimura, E. Konno, S. Yamamoto, T. Watanabe, K. Yamada, and F. Tomonaga, "Formation of recycled plastics from depolymerized monomers derived from waste fiber-reinforced plastics," J. Mater. Cycles. Waste. Manag., vol. 11, pp. 38-41, 2009.

[18] A. Kamimura, E. Konno, S. Yamamoto, T. Watanabe, K. Yamada, and F. Tomonaga, "Improved method for the formation of recycled resins from depolymerized products of waste fiber-reinforced plastics: Simple and effective purification of recovered monomers by washing with water," J. Mater. Cycles. Waste. Manag., vol. 11, pp. 133-137, 2009.

[19] K. Yamada, F. Tomonaga, and A. Kamimura, "Improved preparation of recycled polymers in chemical recycling of fiber reinforced plastics and molding of test product using recycled polymers," $J$. Mater. Cycles. Waste. Manag., vol. 12, pp. 271-274, 2010.

[20] A. Kamimura, K. Kaiso, T. Sugimoto, K. Kashiwagi, T. Watanabe, K. Yamada, and F. Tomonaga, "Supercritical lower alcohols as a useful media for depolymerization," in International Symposium on Sipercritocal Fluid, Arcachon, France, 2009, C32-CO54.

[21] J. Shi, L. Bao, R. Kobayashi, J. Kato, K. Kemmochi, "Reusing recycled fibers in high-value fiberreinforced polymer composites-Improving bending strength by surface cleaning," Compos. Sci. Technol., vol. 72, pp. 1298-1303, 2012.

[22] C. C. Kao, O. Ghita, K. E. Evans, and G. Oliveux, "Mechanical characterisation of glass fibres recycled from thermosetting composites using water-based solvolysis process," in $18^{\text {th }}$ International Conference on Composite Materials, Jeju Island, South Korea, 2011, T8-1-IF0572.

[23] T. Sugeta, S. Nagaoka, K. Otake, and T. Sako, "Decomposition of fiber reinforced plastics using fluid at high temperature and pressure," Kobunshi Ronbunshu, vol. 58, no. 10, pp. 557-563, 2001 (in Japanese).

[24] G. Oliveux, J. L. Bailleul, and E. L. G. L. Salle, "Chemical recycling of glass fibre reinforced composites using subcritical water," Composites: Part A, vol.43, pp. 1809-1818, 2012.

[25] G. Oliveux, J. L. Bailleul, E. L. G. L. Salle, N. Lefèvre, and G. Biotteau, "Recycling of glass fibre reinforced composites using subcritical hydrolysis: Reaction mechanisms and kinetics, influence of the chemical structure of the resin," Polym. Degrad. Stab., vol. 98, pp. 785-800, 2013.

[26] K. Suyama, M. Kubota, M. Shirai, and H. Yoshida, "Degradation of crosslinked unsaturated polyesters in sub-critical water," Polym. Degrad. Stab., vol. 92, pp. 317-322, 2007.

[27] K. Suyama, M. Kubota, M. Shirai, and H. Yoshida, "Chemical recycling of networked polystyrene derivatives using subcritical water in the presence of an aminoalcohol," Polym. Degrad. Stab., vol. 95, pp. 1588-1592, 2010.

[28] T. Nakagawa, T. Urabe, T. Maekawa, M. Hidaka, K. Seto, T. Miyazaki, M. Fukiage, et. al., "Development of FRP material recycling technology through critical water decomposition," Study Results Reporting Meeting 2002 of Joint Research and Development for Environment Protection Technology (Commissioned by the Ministry of Economy Trade and Industry), Nagoya, Aichi, Japan, 2003, pp. 85-90 (in Japanese).

[29] T. Nakagawa, "FRP recycling technology using sub-critical water hydrolysis," JEC Composite Magazine, pp.40-3, Mar.-Apr., 2008.

[30] T. Nakagawa, T. Urabe, T. Miyazaki, M. Hidaka, K. Oka, T. Maekawa, T. Yoshimura, and H. Yoshida, "FRP recycling technology using sub-critical water hydrolysis," in International Symposium on Supercritical Fluid, Kyoto, Kyoto, Japan, 2006, OC-2-08.

[31] T. Nakagawa, T. Urabe, M. Hidaka, T. Maekawa, S. Okumoto, and H. Yoshida, "FRP recycling technology using subcritical water hydrolysis," Network Polymer Journal, vol. 27, no. 2, pp. 28-35, 2006 (in Japanese).

[32] J. W. Tester, H. R. Holgate, F. J. Armellini, P. A. Webley, W. R. Killulea, G. T. Hong, and H. E. Barner, "Oxidation of hazardous organic wastes in supercritical water," ACS Symp Ser, vol. 518, pp. 35-76, 1993. 